\title{
Correspondence
}

To the Editors

\section{Double mutant COVID-19 variant, molecular change and outbreak}

Sri Lanka Journal of Child Health, 2021: 50(3): 565

DOI: http://doi.org/10.4038/sljch.v50i3.9752

(Key words: Double mutant COVID-19 variant, molecular change, outbreak)

Dear Editors,

COVID-19 is an important infection causing more than 140 million infected cases worldwide (data as of April 25, 2021). The molecular evolution of the virus is an important concern in clinical virology. Many mutants or variants of COVID-19 are already reported. The well-known variants are UK, Brazilian and South African variants. Recently, the newest variant, double variant, was firstly reported from India. The new Indian variant is mentioned for increased ability of spreading.

Here, the author would like to discuss the effect of background molecular change of the double mutant COVID-19 on the ability to spread. Regarding mutation, the changes are E484Q and L452R. Based on quantum molecular calculation, the molecular weight change due to E484Q and L452R are equal to -1 and $+43 \mathrm{~g} / \mathrm{Mol}$, respectively. The overall final molecular change is equal to $+42 \mathrm{~g} / \mathrm{Mol}$. Based on the increasing molecular weight, it might mean that required amount of pathogen molecules for interaction with the host receptor decreases. The observation might be an explanation for the increased ability to spread, attributed to the double mutation variant COVID-19. This is the same phenomenon as observed in effects of polymorphisms in many medical disorders. The effect of mutation of SARS-CoV-2 virus is confirmed as an important pathogenetic and underlying molecular property, corresponding to infectivity and response to immune system and $\operatorname{drugs}^{1,2}$.

\section{References}

1. Li Q, Wu J, Nie J, Zhang L, Hao H, Liu S, et al. The impact of mutations in SARSCoV-2 spike on viral infectivity and antigenicity. Cell 2020; 182(5): 1284-94.

2. Wiwanitkit V. SARS-CoV2 variant and effect of therapy. International Journal of Chronic Diseases and Therapy 2020; 6(1e):1.

\author{
*Pathum Sookaromdee ${ }^{1}$; Viroj Wiwanitkit ${ }^{2}$ \\ ${ }^{1}$ Private Academic Consultant \\ ${ }^{2}$ Honorary Professor, Dr. DY Patil University, \\ Pune, India \\ *Correspondence: pathumsook@gmail.com
}

https://orcid.org/0000-0002-8859-5322 